\title{
COLABORAÇÃO INTERCULTURAL NA EDUCAÇÃO SUPERIOR: CONFLITOS E NEGOCIAÇÕES EM EXPERIÊNCIAS NA ARGENTINA, NO BRASIL, NA COLÔMBIA E NO PERU ${ }^{1}$
}

\author{
JOSÉ GUILHERME DOS SANTOS FERNANDES ${ }^{2}$
}

UFPA

\begin{abstract}
RESUMO: Este artigo apresenta resultados de pesquisa pós-doutoral relativa a experiências de colaboração intercultural entre instituições de educação superior e populações indígenas $e$ afrodescendentes em quatro países da América do Sul - Argentina, Brasil, Colômbia e Peru. A partir de fontes bibliográficas e entrevistas com participantes dessas experiências, determinaram-se os seguintes aspectos na investigação: relações institucionais - marcos legais, proponentes e gestores, modelos de propostas interculturais - e proposições epistemológicas e metodológicas - epistemologia e saberes, desenhos curriculares e metodológicos, processos seletivos, avaliação pedagógica. Considerou-se, na análise, preferencialmente os conceitos de colaboração intercultural (MATO, 2008, 2009a, 2009b), região cultural (RAMA, 2001) e ontologia relacional e bom viver (ESCOBAR, 2012). Concluiu-se que, apesar de tensões e conflitos entre atores envolvidos, as experiências merecem continuidade pela possibilidade de inclusão, no espaço acadêmico, da diversidade cultural de saberes e práticas étnicas.
\end{abstract}

\footnotetext{
${ }^{1}$ Este artigo é resultado do desenvolvimento do Projeto de Pesquisa Pós-Doutoral intitulado Experiências de colaboração intercultural entre instituições de ensino superior e populações indígenas $e$ afrodescendentes na América do Sul, aprovado em outubro de 2012, pelo Comitê do Programa de Estudos Pós-Doutorais da Universidad Nacional de Tres de Febrero (PEP/UNTREF), de Buenos Aires (Argentina), sob a supervisão do Prof. Dr. Daniel Mato (CONICET/UNTREF), e com apoio de bolsa de estágio sênior da Coordenadoria de Aperfeiçoamento de Pessoal do Ensino Superior (CAPES/MEC/Brasil), com o objetivo de identificar as características e logros dessas experiências, assim como analisar os principais conflitos e negociações que se apresentaram no desenvolvimento das modalidades de colaboração intercultural. No decorrer da investigação, realizaram-se entrevistas e conversas informais com atores participantes das experiências escolhidas e que merecem meu especial agradecimento tanto como interlocutores como, por que não considerá-los, "coautores"; são eles: na Colômbia, Alexandra Obando, Axel Rojas, Jaime Fayad, Marta Corrales, Miriam Teresa Vidal e Santiago Velasco, da Universidade de Cauca (Popayán), além de Javier Fayad, da Universidade Javeriana (Calli); no Peru, Dubner Medina e Jenny Panduro Urrelo, ambos do Programa FORMABIAP/Instituto Pedagógico Loreto (Iquitos), e Ilana Estabrides Sánchez e Ysabel Cevallos, estas da Direção de Coordenação Universitária do Ministério da Educação Nacional, além de Gavina Córdoba, da Universidade Maior de San Marcos, em Lima; na Argentina, Amada Farias, Ana Fleita, Antonieta Ventura, David Segovia, Estela Maris Valenzuela, Genaro Segundo, Gustavo Salvatierra, Mario Gomez, Otto Guillermo Schmidt e Rubén Paz, todos do CIFMA (Presidencia Roque Sanz Peña); e, finalmente, no Brasil, os professores Fabíola Carvalho e Maxim Repetto, da Universidade Federal do Roraima (Boa Vista), e José Jorge Carvalho, Luciana Hartmann e Rita Honotório, do Projeto Encontro de Saberes, vinculado ao INCTI, da Universidade de Brasília.

${ }^{2}$ Professor Associado I da Universidade Federal do Pará (UFPA), doutor em Letras/Literatura Brasileira (UFPB, 2004), Pós-doutorando da Universidad Nacional de Tres de Febrero (UNTREF, Argentina), Vicecoordenador do PPG em Linguagens e Saberes na Amazônia (PPGLS/UFPA). E-mail: mojuim@uol.com.br.
}

Espaço Ameríndio, Porto Alegre, v. 8, n. 1, p. 10-39, jan./jun. 2014. 
JOSÉ GUILHERME DOS SANTOS FERNANDES - Colaboração intercultural na educação...

PALAVRAS-CHAVE: ColaboraçãoIntercultural; Inclusão de saberes; Educação Superior; América Latina.

\begin{abstract}
This article presents the results of post-doctoral research on the experiences of intercultural collaboration between higher education and indigenous and Afro-descendant populations in four countries of South America - Argentina, Brazil, Colombia and Peru. From literature sources and interviews with participants in these experiments, these points were determined in the investigation: institutional relations - legal frameworks, proponents and managers, models of intercultural proposals - and epistemological and methodological propositions - epistemology and knowledge, curricular and methodological designs, selection processes, pedagogical evaluation. It is considered in the analysis, preferably the concepts of intercultural collaboration (MATO, 2008, 2009a, 2009b), cultural region (RAMA, 2001) and relational ontology and good living (ESCOBAR, 2012). It was concluded that, although tensions and conflicts between actors involved, the experiences deserve continuity for possible inclusion into academic space, cultural diversity of knowledge and ethnic practices.
\end{abstract}

KEYWORDS: Intercultural Collaboration; Inclusion of knowledge; Higher Education; Latin America.

Entende-se por colaboração intercultural a relação entre culturas mediante o diálogo e o reconhecimento mútuo de seus valores e modos de vida, no sentido de se alcançar a solidariedade criativa, sem necessariamente ocorrer a fusão das culturas ${ }^{3}$. Por certo, existem experiências em universidades latino-americanas que se orientam aparentemente para a interculturalidade, mas de fato se limitam a oferecer programas de bolsas e cotas visando pequenos contingentes de indivíduos de populações indígenas e afrodescendentes, como meio de garantir o ingresso, aprimoramento acadêmico e progressão na academia. Essas iniciativas mais comuns não são sem valor, mas são unilaterais e não representam a colaboração entre diversas culturas; basicamente são iniciativas de inclusão de indivíduos indígenas e

\footnotetext{
${ }^{3}$ Consideraremos o sentido de interculturalidade conforme o que dispõe o Centro Virtual Cervantes, em seu dicionário: "La interculturalidad es un tipo de relación que se establece intencionalmente entre culturas y que propugna el diálogo y el encuentro entre ellas a partir del reconocimiento mutuo de sus respectivos valores y formas de vida. No se propone fundir las identidades de las culturas involucradas en una identidad única sino que pretende reforzarlas y enriquecerlas creativa y solidariamente. El concepto incluye también las relaciones que se establecen entre personas pertenecientes a diferentes grupos étnicos, sociales, profesionales, de género, etc. dentro de las fronteras de una misma comunidad. En el ámbito general de la enseñanza, esta actitud propugna el desarrollo de valores sociales. La interculturalidad se ha introducido de manera explícita en el currículo de diversas instituciones como parte integrante de los contenidos referidos a los procedimientos y a las actitudes, los valores y las normas" (CENTRO VIRTUAL CERVANTES, s./d., n./p).
}

Espaço Ameríndio, Porto Alegre, v. 8, n. 1, p. 10-39, jan./jun. 2014. 
JOSÉ GUILHERME DOS SANTOS FERNANDES - Colaboração intercultural na educação...

afrodescendentes em universidades "convencionais". Embora, em princípio, essas iniciativas, que garantem o acesso e a melhoria dos estudos de indivíduos indígenas e afrodescendentes, sejam valiosas, a médio e longo prazo não o são, porque não incorporam efetivamente o conhecimento proveniente da diversidade cultural. As ideias de colaboração intercultural que orientam as experiências que estudamos costumam partir da proposição de que a integração de conteúdos de diversas origens culturais deve ser desenvolvida no âmbito das práticas pedagógicas e de investigação, orientadas a evitar que uma orientação cultural prevaleça sobre as demais. Em geral, há o reconhecimento de que "não existe saber universal, nenhum o é; todos são relativos às condições em que são produzidos" (MATO, 2008, p. 106).

Nesta investigação, objetivou-se traçar um quadro de convergências e divergências entre as experiências discriminadas, focando-se aspectos de relações institucionais e aspectos de proposições epistemológicas. Nossa contribuição vem ao encontro da necessidade de gerar conhecimentos e promover reflexões e diálogos acerca de como melhorar a inclusão de saberes, línguas, histórias e visões de mundo das populações indígenas e afrodescendentes na educação superior, pública e/ou privada, a partir de avaliação de experiências que podem servir de referência para a melhoria de propostas pedagógicas de instituições interessadas. Uma questão nos foi determinante: a necessidade de "interculturalizar" a educação superior implica não somente incluir indivíduos de populações indígenas e afrodescendentes em instituições de educação superior, com ou sem seus saberes e práticas, mas implica principalmente em propor-se outras possibilidades de produção de conhecimentos nas universidades modernas, em profícuo diálogo entre as várias epistemologias, sejam estas universalistas ou aborígenes.

Nossa investigação acerca das experiências de colaboração intercultural não só poderá ser uma contribuição para a academia, no sentido de tornar visíveis algumas práticas existentes e ajudar nossas reflexões sobre o que necessitamos para ampliar a colaboração intercultural de saberes, mas também poderá ser uma contribuição para a compreensão da diversidade cultural na América Latina. 
JOSÉ GUILHERME DOS SANTOS FERNANDES - Colaboração intercultural na educação...

\section{Da escolha das experiências}

A fim de realizar a investigação, além de revisão bibliográfica sobre estudos já realizados de experiências de colaboração e sobre referenciais teóricos (contemplados em parte na bibliografia deste artigo), optou-se por entrevistas in loco com atores e instituições participantes de experiências de colaboração intercultural, as quais foram realizadas em maio/junho e outubro/novembro de 2013. Em princípio, a escolha de quatro países da América do Sul - Argentina, Brasil, Colômbia e Peru - foi determinada em função de que havia experiências significativas, e de algum tempo, nestes países, particularmente na Universidade de Cauca (Colômbia), mediante a licenciatura em Etnoeducación (ver ROJAS, 2008a), em funcionamento desde 1995, na cidade de Popayán; o Programa de Formación de Maestros Bilingües de la Amazonía Peruana/FORMABIAP (ver TRAPNELL, 2008a), vinculado ao Instituto Superior Pedagógico Público Loreto, em Iquitos (Peru), desde 1987; e o Profesorado Intercultural Bilingüe para La Educación Primaria, do Centro de Investigação e Formação para a Modalidade Aborígene/CIFMA (ver VALENZUELA, 2009), na cidade de Presidência Roque Sanz Peña, na Província de Chaco, na Argentina, atuante desde 1988. No Brasil, em 2002 foi instituída uma das primeiras licenciaturas interculturais mediante o Núcleo Insikiran de Formação Superior Indígena, da Universidade Federal de Roraima (UFRR), na cidade de Boa Vista, capital do estado, que foi o foco de nossa pesquisa neste país. Mas vale ressaltar que em Brasília, desde 2009, desenvolve-se um projeto de inclusão de saberes da cultura popular, em especial a partir das ações afirmativas de cotas para indígenas e afrodescendentes, iniciativa desenvolvida pelo Projeto Encontro de Saberes, vinculado ao Instituto Nacional de Ciência e Tecnologia de Inclusão no Ensino Superior e na Pesquisa/INCTI, da Universidade de Brasília (UnB), na capital federal do Brasil, que abordaremos tangencialmente. Sendo assim, nossa escolha por estas experiências procurou contemplar a diversidade de países, de tempo cronológico de existência e de modalidade de colaboração acadêmica (universidade ou instituto superior, colaboração institucionalizada ou colaboração eventual, 
JOSÉ GUILHERME DOS SANTOS FERNANDES - Colaboração intercultural na educação...

instituição/universidade convencional ou instituição/universidade própria) ${ }^{4}$.

A escolha por estas experiências também contemplou a diversidade de regiões culturais na América do Sul, o que implicou em se ter diferentes processos históricos, sociais e culturais representados e comparados para que se configure um cenário mais amplo do universo de experiências de referência, que inclui a diversidade étnica, política e de tendências diversas no domínio da educação e colaboração intercultural. Entende-se que a unidade latino-americana é um projeto de intelectuais e está calcada em um passado que aponta para uma história comum a línguas e a comportamentos indiferenciados, o que é próprio do centrismo colonizador, no caso o europeu. Lembra Rama que "sob essa unidade, real como projeto, real quanto às bases de sustentação, desdobra-se uma interior diversidade que é a definição mais precisa do continente" (2001, p. 281). Há de se reconhecer que a unidade nacional implica em diferenciações não só em relação às culturas externas, mas que também existem diferenciações internas, tocadas por critérios que "levam em conta o meio físico, a composição étnica da população, a produção econômica dominante, o sistema social derivado, os componentes culturais modeladores e transmitidos dentro desses limites" (RAMA, 2001, p. 285). Não se pode confundir as pretensas características e necessidades comuns de estados nacionais, decorrentes de processos coloniais e pós-coloniais, com as populações contidas nestes, o que somente oferece um tratamento homogêneo destas populações. Deve-se ter em consideração o que diz Mato:

Las organizaciones sociales y políticas indígenas y afrodescendientes contemporáneas son muy heterogéneas entre sí, como consecuencia tanto de los muy diversos pueblos de los que emergen, como de las diferencias de los contextos nacionales y de sus relaciones con los respectivos Estados, y otros actores sociales, así como de los idearios de sus respectivos liderazgos. Reconocer esta heterogeneidad es

\footnotetext{
${ }^{4}$ Consideraremos universidade própria ou intercultural conforme a classificação de Mato (2012, p. 11) como Instituição Intercultural de Educação Superior (IIES); vale lembrar o autor: "Llamamos IES 'convencionales' a aquellas cuyos planes de estudio no incluyen los saberes, lenguas, historias y visiones de mundo de los pueblos indígenas y afrodescendientes, y llamamos instituciones interculturales de Educación Superior (IIES) a aquellas cuyos planes de estudio los integran junto con los propios de las disciplinas científicas y humanísticas 'occidentales"”.
}

Espaço Ameríndio, Porto Alegre, v. 8, n. 1, p. 10-39, jan./jun. 2014. 
JOSÉ GUILHERME DOS SANTOS FERNANDES - Colaboração intercultural na educação...

fundamental para valorar apropiadamente las iniciativas en educación superior que han impulsado organizaciones y sectores particulares de estos movimientos sociales, así como para evitar la tentación de pensar en "modelos" a emular (MATO, 2012, p. 22).

\section{Da invisibilização do afrodescendente}

Como a proposta da investigação em que se baseia este artigo é tratar não somente do indígena, necessito primeiramente me referir ao silenciamento e ocultamento históricos das populações afrodescendentes quando se estuda as populações formadoras da América Latina. Tomemos o exemplo da Colômbia e do Brasil, dois países que apresentam relevante população de negros. $O$ reconhecimento e a autonomia das populações afrodescendentes, na Colômbia, em relação à existência de educação, de território e de práticas culturais próprias não foram além da Lei 70/1993, que garantiu a propriedade de terras das populações negras da costa do Pacífico, assim como o fomento de seu desenvolvimento econômico e social. Isso porque, contrariamente ao que ocorreu com as populações indígenas neste país, que lutaram e obtiveram logros em relação ao seu reconhecimento e autonomia, mesmo a despeito de serem "minoria" (cerca de $4 \%$ da população), os afrodescendentes não foram além de cotas e bolsas nas universidades "convencionais". Nas palavras de Marta Corrales, professora e uma das organizadoras da Licenciatura em Etnoeducação da Universidade de Cauca, "Ios pueblos afrocolombianos están muy fragmentados (...). Hay muchos grupitos que no dialogan, se contradicen". Da mesma forma, Axel Rojas, professor e um dos proeminentes investigadores do afrocolombianismo, nesta mesma universidade, pergunta, em tom de uma possível resposta contraditória: “¿Por qué lo étnico era pensado en términos indígenas? ¿Por qué lo negro no era pensado como lo étnico?". Ao que parece, assim como em Colômbia, nos demais países investigados o que podemos considerar como colaboração intercultural em relação aos afrodescendentes se restringe a cotas e bolsas em cursos superiores. Até o presente momento, o que existe é tênue discussão sobre a inclusão de saberes destas populações ou a organização de universidades interculturais 
JOSÉ GUILHERME DOS SANTOS FERNANDES - Colaboração intercultural na educação...

afrodescendentes.

Há uma invisibilização do negro nessa discussão mais ampla acerca da inclusão de práticas e saberes. Mesmo no Brasil, onde existe uma reconhecida maioria de população afrodescendente em números reais (51\% declarado da população), em relação aos demais países latino-americanos, o máximo que se avançou foi a lei 10.639/20035, que promulgou a obrigatoriedade, no currículo da rede de ensino oficial, da história e da cultura afro-brasileiras, considerando-se tão-somente as áreas de Educação Artística, Literatura e História Brasileiras. Também na Colômbia, outro reconhecido país de significativa população afrodescendente, estabeleceu-se algo semelhante ao Brasil, a Cátedra de Estudos Afrocolombianos, pelo decreto 1122/1998, nos níveis préescolar, básico e médio em todas as escolas, para ser desenvolvida como atividade transversal em várias áreas, afetando todo o planejamento curricular. Mas o que tem ocorrido é a disciplinarização da Cátedra, sendo esta efêmera, isolada de outras disciplinas e sem continuidade para a comunidade de interesse; e isso quando a Cátedra se efetiva de alguma maneira, pois mesmo que seja obrigatória têm ocorrido escassas ações para sua implementação (ROJAS, 2008b).

No Brasil, além da lei 10.639/2003, existe a obrigatoriedade de reserva de $50 \%$ de vagas em instituições federais de ensino superior a estudantes que cursaram o ensino médio na rede pública, na maioria negros e mestiços, mas sem a garantia de inclusão de saberes afrodescendentes. Mesmo na Faculdade Palmares, na cidade de São Paulo (Brasil), idealizada e administrada por negros, fundada em 2003 como baluarte da inclusão destes, não se realiza efetivamente a inclusão de saberes afrodescendentes, limitando-se a consolidar os alunos no "mercado competitivo", mediante cursos destinados a carreiras para a sociedade globalizada, como administração, direito e publicidade e propaganda: é uma universidade convencional tingida de preto!

Resumidamente, não obtivemos sucesso em investigar a colaboração intercultural em relação aos afrodescendentes, pelas seguintes razões:

a) A organização civil das comunidades afrodescendentes ainda se

\footnotetext{
${ }^{5}$ A lei $11.645 / 08$ altera a lei 10.639/03, acrescentando ao texto a obrigatoriedade também do estudo da história e da cultura indígenas.
}

Espaço Ameríndio, Porto Alegre, v. 8, n. 1, p. 10-39, jan./jun. 2014. 
JOSÉ GUILHERME DOS SANTOS FERNANDES - Colaboração intercultural na educação...

apresenta em estágio muito inicial, sem a necessária força coesiva e reivindicatória para incomodar a hegemonia cultural e política, sendo pouco influente para efetivar propostas de colaboração intercultural, contrariamente ao que desde cedo foi alcançado pelos indígenas. Talvez como resultante deste fator, ou mesmo como causa dele, a maioria dos pesquisadores na universidade e na educação superior vem de uma acentuada tradição de investigação étnica indígena, pouco afeita às populações afrodescendentes. Talvez a forma de organização e resistência política das comunidades afrodescendentes deva ser considerada como um outro modelo, distinto das palavras de ordem e dos movimentos do campesino-indígena: "la población negra no tenemos una movilización más en términos de ir a la calle confrontar, sino que es tocar un tambor, es la percusión, es la música; y seguir en el territorio es una forma de resistencia distinta" (Amanda Hurtado Garces, estudante afrodescendente de antropologia na Universidade de Cauca).

b) Existe uma visão purista de práticas e saberes afrodescendentes, aos moldes do que se convencionou em relação aos indígenas. $\mathrm{E}$ isso tem implicado em se querer encontrar uma cultura e comunidade afrodescendente isolada e infensa aos contatos culturais, a exemplo dos indígenas que, no processo de colonização e como fuga aos espanhóis, se lançaram tierradentro. Em realidade, muitas vezes, e tenho o Brasil como exemplo, as comunidades indígenas tiveram estreito contato com negros escravizados e fugidos das plantations e fazendas, momento em que se estabeleceu um hibridismo entre essas populações. Por isso, por mais que haja comunidades palenqueras, em Colômbia, ou quilombolas, em Brasil, localizadas em lugares isolados, originadas da fuga de negros escravizados, como garantia de sobrevivência autônoma à margem de sociedades colonizadoras, em parte as comunidades afro também são fruto de contatos étnicos que originaram inclusive línguas crioulas e práticas mestiças, em maior ou menor grau. Tive prova disso no $V$ Seminário Povos Indígenas $e$ Sustentabilidade, na cidade de Campo Grande (Mato Grosso do Sul, Brasil), ocorrido em setembro de 2013, quando ao indagar o indígena terena Antonio Carlos Seizer sobre a natureza desses contatos interculturais, ele afirmou que se reconhecia indígena, mas também era praticante da umbanda. Mas o fato mais alarmante é que em Colômbia, 
JOSÉ GUILHERME DOS SANTOS FERNANDES - Colaboração intercultural na educação...

particularmente, a Constituição Política de 1991 não garante os palenques como entidades territoriais e autônomas em sua gestão, ao contrário do reconhecimento nesta condição de territórios indígenas, conforme artigo 286. Na constituição brasileira também ocorre o mesmo.

c) Como resultante de toda essa incompreensão da localidade do afrodescendente face às demais populações da América Latina, no aspecto legal creio que haja equívocos interpretativos para considerar o afrodescendente como população "indígena" ou pelo menos sociedade tribal. A Convenção 169 da OIT, aceita amplamente pelos países latinoamericanos em suas constituições políticas, aplica-se, para além dos povos indígenas (populações que habitavam determinado território por ocasião da conquista ou colonização), aos considerados povos tribais, estes regidos total ou parcialmente por seus próprios costumes e tradições. Tribo é uma sociedade regida pelas relações de parentesco e hierarquia mais "simples", sem a autoridade centralizada do Estado moderno, com certa autonomia institucional e com homogeneidade de práticas laborais, permanecendo em um mesmo território por gerações. Ora, os afrodescendentes, desde cedo e na maioria dos casos, são uma população que foi despossuída em sua diáspora. Esses indivíduos tiveram que compor uma nova língua e cultura pelos rastros/resíduos de suas origens (GLISSANT, 2005), mas de uma forma imprevisível, pois o que foi gerado deveria ser válido para todos aqueles despossuídos, e isso implicou em um acréscimo cotidiano e permanente nessa cultura e língua crioulas, compósitas e nascidas do contato com o heterogêneo. Acrescente-se a isso que foram transplantados e por isso também não são considerados aborígenes, e muito menos tiveram um "território" para construir uma ancestralidade mais coesa, mesmo porque foram postos em contato mais direto com o colonizador, nas cidades. Portanto, considerar o conceito de povo tribal, aos moldes clássicos do que seja uma tribo, é no mínimo desconsiderar esse processo histórico, o que reforça as palavras da estudante Amanda Garces: "las poblaciones blancas, mestizas, indígenas desconocen realmente la historia del negro. Y la historia que conocen del negro es una historia racista, que nos hay bestializado y selvatizado". Creio pela necessidade de se reconceituar a condição do negro, mais como população diaspórica e 
JOSÉ GUILHERME DOS SANTOS FERNANDES - Colaboração intercultural na educação...

assimilada ao heterogêneo. Ou, por outro lado, considerar a categoria indígena como menos étnica e mais supraétnica, ou seja, uma categoria estrutural na sociedade colonial global. Mas isso deve ser apanágio de um outro estudo. Por momento basta dizer que o resultado disso é a invisibilização do afrodescendente, e por isso não poderei tratar da inclusão do mesmo com especificidade neste trabalho, mesmo porque inexistem experiências de ensino superior intercultural consolidadas nas realidades pesquisadas.

\section{Das relações institucionais: contradições e conflitos}

É interessante observar que em todas as constituições dos países pesquisados existe o reconhecimento da autonomia dos indígenas, das comunidades campesinas e nativas, dos grupos étnicos e das manifestações culturais diversas, a exemplo das constituições do Brasil (1988), da Colômbia (1991) e do Peru (1993), e da reforma constitucional da Argentina (1994). O discurso oficial é o do reconhecimento da diversidade e da igualdade de todas as culturas que compõem as nações e da capacidade civil dos indígenas, garantindo-se o direito ao território, à cultura e à educação próprias, à assistência à saúde conforme suas práticas e necessidades, à sobrevivência segundo suas tradições.

Não obstante, nas próprias legislações há contradições, referentes aos marcos legais. No Brasil, com população autodeclarada indígena de 817.963 indivíduos (Censo Demográfico, 2010, IBGE/Brasil), e com 274 línguas faladas em 305 etnias diferentes, a constituição federal reconhece somente a língua portuguesa como oficial (art. 13), mesmo que o artigo 215 da mesma legislação garanta que "o Estado protegerá as manifestações das culturas populares, indígenas e afrodescendentes". Também no Brasil, as terras indígenas são consideradas bens da União, pertencendo ao estado nacional (artigo 20, inciso XI). De outro modo, a constituição política do Peru, no artigo $2^{\circ}$, inciso 19, reconhece a pluralidade étnica e cultural da nação, inclusive garantindo como oficial as línguas quéchua, aimara e outras aborígenes nos territórios em que predominem (artigo 48). Na Colômbia, a 
JOSÉ GUILHERME DOS SANTOS FERNANDES - Colaboração intercultural na educação...

constituição política coloca as terras indígenas como entidades territoriais (artigo 286), em igualdade com os departamentos e com autonomia administrativa, além do que garante a oficialidade de línguas e dialetos de grupos étnicos em seus territórios (artigo $7^{\circ}$ ). $\mathrm{Na}$ Argentina, existe o reconhecimento indireto de línguas indígenas como oficiais, uma vez que o artigo 75, inciso 17 , reconhece a pré-existência étnica e cultural dos indígenas, garantindo educação bilíngue e intercultural; também garante a personalidade jurídica das comunidades e a propriedade comunitárias das terras.

Mas não pensemos que os aparentes avanços no Peru, na Colômbia e na Argentina, em relação ao Brasil, são sem contradições. Aqui aparecem as incongruências sociais e burocráticas. Na Colômbia, o artigo 68 garante a formação diferenciada de pessoas integrantes de grupos étnicos, conforme sua identidade cultural. Mas o grande impasse para o reconhecimento de universidades interculturais e próprias, ou seja, de origem e formação por populações indígenas, é que a lei 30 , que organiza a educação superior, não reconhece a existência dessa modalidade de universidade em seu Sistema Nacional de Informação da Educação Superior, que discrimina as características das instituições. Ademais, esbarra-se na autonomia universitária, uma vez que as instituições superiores devem ter independência política, econômica e administrativa em relação a outras instituições, para que haja autonomia na geração de conhecimentos. O problema é que, em Colômbia, a existência de universidades indígenas está vinculada a organizações indígenas, como o CRIC (Conselho Regional Indígena de Cauca), que está na origem da Misak Universidad, no resguardo de Santiago, em Silvia, departamento de Cauca. Nesta universidade, por ocasião do evento Minga por la educación ancestral, ocorrido entre 31 de maio e 2 de junho de 2013, com a finalidade de se discutir, entre populações indígenas e o ministério da educação nacional, o modelo de universidade própria, as palavras da representante do ministério, em sua conferência, refletem a visão do estado colombiano: "el adjetivo no puede primar sobre el sustantivo" (Olga Sanchez, Ministério da Educação Nacional, Colômbia). Ou seja, não se pode pensar em outro modelo de instituição superior sem que haja uma estrita vinculação ao próprio mundo acadêmico, o que reflete o pensamento ocidental sobre $a$ 
JOSÉ GUILHERME DOS SANTOS FERNANDES - Colaboração intercultural na educação...

produção do conhecimento na universidade: independente de qualquer demanda e ingerência mais sociais.

Neste particular, a experiência da Licenciatura Intercultural em Roraima (Brasil) demonstrou mais avanço, pois na administração do Núcleo Insikiran as organizações indígenas locais participam do conselho que rege o núcleo; e, além disso, o curso "foi forjado e mantido a partir de uma reivindicação e de um constante diálogo estabelecido entre setores da UFRR, várias instituições públicas e as organizações indígenas do estado" (CARVALHO, FERNANDES e REPETTO, 2008, p. 16). Mas essa experiência de gestão compartilhada também tem os seus conflitos, pois as representações de instituições públicas no conselho do Insikiran, a exemplo da Fundação Nacional do Índio e das secretarias de educação, são direcionadoras do discurso e da prática do estado na administração do núcleo, muitas vezes forçando a implementação das políticas de governo quanto à educação indígena, como a unificação de modelos de ingresso e de avaliação do ensino superior, desconsiderando-se as particularidades das populações indígenas do Brasil, no tocante à sua história e acesso à educação.

Na Argentina, mesmo que se afirme a garantia a uma educação própria, há tímida discussão acerca de universidades indígenas. $O$ que há são institutos superiores, a exemplo do CIFMA, mas que têm proposições e ações administrativas, curriculares e epistemológicas restritas ao seu entorno local e regional. Muito recentemente, no ano de 2013, houve o encaminhamento para a Câmara de Deputados de projeto de lei discorrendo sobre a criação da Universidade Nacional Intercultural dos Povos Indígenas, de autoria da deputada Alcira Argumedo e com a colaboração de dirigentes, organizações e coletivos indígenas, muito embora este projeto não tenha sido aprovado.

No Peru, foram aprovadas, pelos congressistas, quatro universidades interculturais, nas cidades de Cusco, Bagua, Junín e Ucayali, mas que não têm legalidade de funcionamento, uma vez que foram criadas como interculturais somente na designação. Isto porque a lei que rege a educação superior no Peru não discrimina essa modalidade de universidade, somente as nacionais e as privadas. Ou seja, "en el Congreso se hacen las leyes de creación y muchas veces se hacen esas leyes más por razones de orden político que por razones de 
JOSÉ GUILHERME DOS SANTOS FERNANDES - Colaboração intercultural na educação...

necesidad real de los pueblos" (Ilana Estabrides Sanchez, Diretora de Coordenação Universitária, Ministério da Educação, Peru). Esta situação reflete o descompromisso dos políticos, unicamente preocupados em fazer promessas em campanhas eleitorais, sem mesmo atentar para a legalidade das propostas.

Com o exemplo peruano podemos ressaltar outro aspecto desta investigação, relacionado às relações institucionais, que são os proponentes e gestores das experiências de colaboração intercultural. Primeiramente, devemos observar que há diferença entre as propostas construídas a partir de demandas dos indígenas e efetiva participação destes na construção, de um lado; e propostas elaboradas por personagens e instituições externas às populações indígenas, de outro lado. No primeiro caso a efetivação dos cursos é mais delongada, uma vez que requer amplo e extenso diálogo entre instituições educativas e organizações indígenas, por vezes sem muitos avanços, como é o caso da Misak Universidad, ou mesmo de institutos superiores já com largo tempo de existência, como o CIFMA ou o Programa FORMABIAP, do Instituto Pedagógico Loreto: ainda hoje, no caso destes, há indefinição quanto às competências do estado ou das organizações. Segundo o professor Dubner Medina, coordenador do FORMABIAP pelo Instituto Pedagógico Loreto, "hasta ahora casi el estado muy poco hay participado de la vida de esta institución", o que se reflete unicamente no pagamento de salários a alguns professores atuantes no programa. De todo modo, acreditamos que a participação efetiva de todos os interessados seja menos perigosa, por mais que seja uma luta contínua. No caso de iniciativas a partir de intelectuais orgânicos de instituições superiores convencionais ou mesmo pela iniciativa de políticos, ao que parece são proposições meramente efêmeras e sem sustentação de um modelo mais alternativo às universidades convencionais. Creio mesmo que deva haver o que ocorreu na proposição da deputada argentina Argumedo, quando, a partir de demandas indígenas e com o respaldo investigativo e epistemológico destes e de intelectuais acadêmicos, se propôs, pela via política, a existência de universidades próprias. Devemos lembrar o que afirmou Marta Corrales (Universidade de Cauca) quanto à origem da licenciatura em Etnoeducação: "Creo que ha sido fundamental las exigencias y las demandas de las organizaciones 
JOSÉ GUILHERME DOS SANTOS FERNANDES - Colaboração intercultural na educação...

indígenas". Somente assim pode-se ter ampla participação de interessados, e a existência legal das universidades, com regras adequadas à formação de seu quadro docente e de investigação, à sua administração, ao aporte epistemológico, aos recursos financeiros e às formas de ingresso e avaliação.

Quanto à gestão, não se pode tratar desta sem ingressar em outro ponto das relações institucionais: modelos de propostas interculturais. Há de se tratar da diferença entre proposições de universidades e de institutos. As experiências de mais prolongada existência investigadas são referentes aos institutos superiores, como é o caso do Peru e da Argentina. Estes surgem de iniciativas mais locais ou regionais, com o mérito de responderem às necessidades imediatas de uma população indígena necessitada de formação adequada para seus infantes e adolescentes, mesmo porque a educação é a garantia mínima de permanência de uma cultura. Por isso, as experiências do CIFMA e do FORMABIAP surgem, há mais de 25 anos, como resposta aos indígenas por uma educação bilíngue e intercultural, que revalorizasse as culturas indígenas mediante a formação e educação das novas gerações. No entanto, observamos que os institutos não têm ido além porque não se inserem como política educativa de alcance nacional até o momento, desconhecendo-se suas experiências afora de seus muros. Mesmo nas cidades de Presidência Roque Sanz Peña e de Iquitos há dificuldade, em princípio, em se saber a localização dos institutos, pois parte da população desconhece sua existência nestas cidades de médio porte: "algunos, para decir la verdad, no saben que existe CIFMA. Son enterados muy poco, y eso que nosotros, de alguna manera, para fechas significativas, salimos a la ciudad a dar charlas en las escuelas, y mostrar la presencia indígena en la formación docente" (Estela Maris Valenzuela, coordenadora pedagógica e reitora do CIFMA). Valenzuela também lembra de certo estudante de colégio na cidade de Roque Sanz Peña, que durante uma conversa, afirmou: "Pero los indígenas ya no viven más, no hay más indígenas". São discursos que não tiram o mérito destas iniciativas conformadas pelos institutos, mas que reiteram a necessidade de se fazer propostas interculturais de alcance nacional.

Ao que parece será a partir dessas iniciativas mais localizadas que se fará coro a uma proposição mais abrangente nos países investigados, 
JOSÉ GUILHERME DOS SANTOS FERNANDES - Colaboração intercultural na educação...

pois do contrário existe muita resistência nas universidades convencionais para se aceitar propostas mais inovadoras como a de educação intercultural, o que somente é factível nas instituições chamadas de periféricas, particularmente institutos. Nas universidades convencionais o que se tem avançado mais é na proposição de cotas, com reserva de vagas, como é o caso brasileiro; ou na oferta de bolsas de estudos, como é o caso peruano. Mesmo neste último caso há muito desacerto, pois o Programa Beca 18, do Ministério da Educação do Peru, inicialmente destinou bolsas somente para as universidades, ficando de fora os institutos; posteriormente, estendeu-se a estes, mas sem obedecer às particularidades da formação de professores indígenas, que ocorre em modelo de alternância (parte do tempo de formação na escola e parte na comunidade de origem), o que implicou em edital que não respeitou os prazos e períodos dessa alternância: resultado foi que poucos professores indígenas em formação participaram do processo de seleção para as bolsas. Mais uma vez a incoerência é resultado do desconhecimento das propostas pedagógicas interculturais e das experiências dos institutos, decorrentes de uma política educacional unificadora.

Em vista dessas questões, inerentes aos modelos de propostas interculturais, há de se considerar a necessidade de unificação de política educacional específica para a área, e referente à gestão, que contemple a especificidade das propostas interculturais, como: a administração compartilhada entre instituições superiores de educação e organizações indígenas; o calendário administrativo e curricular específicos; o ingresso de docentes de diversos saberes e formações para atuarem como formadores; o orçamento adequado à dinâmica de acompanhamento dos formandos e à produção específica de material didático; dentre outras especificidades. Outro aspecto dos modelos a se considerar é em relação ao tipo de interculturalidade, considerando-se que há propostas: bilíngues, de uma única etnia, que dialoga com a língua e cultura do colonizador (espanhol ou português); ou plurilíngues, de mais de uma etnia, que dialogam com a língua e cultura do colonizador a partir de várias línguas aborígenes. Saber qual o modelo mais adequado implica em se determinar qual o conceito de interculturalidade a ser considerado na construção da proposta. 
Também, referente ao modelo de instituição implementadora de interculturalidade, deve-se observar que não somente universidades próprias merecem a atenção na implementação de diálogo intercultural, uma vez que nem todos os indígenas têm a pretensão de realizar cursos específicos nestas possíveis universidades ou institutos: a questão é que não se pode negar aos jovens indígenas a possibilidade de terem a formação em universidades convencionais, como lembra Alexandra Obando (estudante indígena de Filosofia da Universidade de Cauca e dirigente do cabildo universitário):

Tenemos que pensar en los compañeros que van a salir de resguardo y que van a querer estudiar otra cosa en una universidad convencional (...). Entonces concebimos que es necesario que se piense también en ese sistema aplicado a las universidades convencionales.

Deve-se ter em conta a interculturalização de universidades convencionais, mediante seus cursos "clássicos", como direito, engenharia ou medicina, com a inclusão de práticas e saberes diversos, a exemplo da proposta do Programa Encontro de Saberes, da Universidade de Brasília (Brasil).

Por outro lado, em relação a propostas interculturais plurivalentes, a presença, em um mesmo espaço de aprendizagem, de indígenas com diferentes graus de envolvimento com sua cultura própria ou com a cultura urbana e não indígena pode gerar tensões e incompreensões do processo de "branqueamento" de cada etnia, implicando em valorações que têm a língua ou cultura oficiais como parâmetro do que é o certo. Exemplo é o CIFMA:

Los alumnos wichí, por ejemplo, son alumnos muy conservados, poco comunicativos, son más cerrados en la comunicación, ellos se comunican en su lengua (...). Los alumnos toba saben mucho más el español, entonces tienen un nivel de expresión mucho más fluido. Entonces cuando los wichí se expresan de alguna manera hay burla, hay ironía y demás (...). En albergue, respecto a la tranquilidad, a los toba les gusta escuchar música, reírse, bailar, y a los wichí no, a los mocoví tampoco" (Estela Valenzuela, Argentina). 
Além de tensões interétnicas, há indícios de tensões entre alguns estudantes indígenas, de "certa" etnia, e a administração do CIFMA, decorrente de acusações por aqueles de mau tratamento no albergue da instituição e no comedor, além da oferta mínima de horas em cátedras de docentes indígenas. Ainda segundo os indígenas, os que reclamaram da situação sofreram sanções de suspensão (Cf. POCNOLEC, 2013). Sem entrar no mérito específico da questão, ao que parece algumas etnias são mais permeáveis às relações burocráticas e culturais com os hegemônicos do que outras, conforme suas histórias de contato cultural, o que podemos observar no caso dos Toba e dos Wichí, e isso deve ser observado na proposição de instituições interculturais. É bom lembrar que o que seria bastante proveitoso, a diversidade de línguas e culturas em sala de aula, corre o risco de ser perigoso ao provocar a intolerância na convivência, decorrente da desigualdade no tratamento entre os atores do processo:

Lo cierto parece ser que los docentes suelen no tener elementos didácticos para aprovechar efectivamente la coexistencia de varias lenguas en el aula. Un claro ejemplo de estas cuestiones son las disputas en torno a las competencias lingüísticas a las que se apela para caracterizar a los niños indígenas y migrantes como "bilingües", "multilingües" o "monolingües", así como las consecuencias que tienen esos etiquetamientos para luego catalogarlos como "tímidos", "silenciosos" o "abúlicos" (DIEZ et al, 2011, p. 268).

\section{Proposições epistemológicas e metodológicas}

Para além da rota jurídica e das relações institucionais e administrativas na configuração das experiências de colaboração intercultural, existe o aspecto mais acadêmico, da efetivação em práticas educativas. Isto porque existe muita discussão legal e pouca acadêmica, particularmente em relação aos desenhos curriculares: "la calidad de los proyectos de desarrollo institucional que se han venido diseñando han sido bastante pobres" (Ilana Estabrides, Ministério de Educação, Peru). Afinal, pergunta-se: o que pode existir de específico nos currículos e processos relativo à educação intercultural? Como se 
JOSÉ GUILHERME DOS SANTOS FERNANDES - Colaboração intercultural na educação...

pode efetivar o diálogo intercultural de saberes? Uma resposta mais objetiva não há, mas tomarmos como exemplo as experiências investigadas é um bom começo.

Um dos maiores desafios são as proposições epistemológicas, o que por certo será no modelo universitário em que haverá maior avanço, e maiores dificuldades, em planificar a questão, uma vez que a interculturalidade, quando posta em meio acadêmico universitário, apresenta nuances que podem favorecer a construção de uma educação mais relacional e menos universal: "ontologías relacionales son aquellas que evitan la división entre naturaleza y cultura, entre individuo y comunidad, y entre nosotros y ellos que son fundamentales para la ontología moderna" (ESCOBAR, 2012, p. 37). Entendemos que a ontologia relacional pode favorecer o diálogo de saberes no currículo e na prática pedagógica. Em entrevista, o professor Javier Fayad, da Pontifícia Universidad Javeriana de Calli (Colômbia), lembrando Guillermo Bonfil Batalla, afirma que:

Para hacer relaciones de conocimientos entre distintas culturas hay que trabajar tres elementos: la equivalencia, la variabilidad y la diferencia. La equivalencia porque en la interculturalidad (...), en prácticas comunes va a necesitar trabajar sobre equivalentes para el conocimiento. La variabilidad porque la riqueza de las culturas no es la igualdad ni la identidad, sino la diferencia. La diferencia porque primero identificase usted y sobre esa identidad de yo véase como se relaciona con el otro.

Pode-se compreender, a partir desta concepção, que existem limites para a tradução entre culturas, pois a interculturalidade requer que saibamos que há elemento intracultural em cada saber isolado e posto em contato, que é parte da estrutura do pensamento do grupo social, e isso, muitas vezes, é intraduzível para outro grupo social, como, por exemplo, certos termos de uma língua, como exemplo a palavra "saudade" em português, "intraduzível" ipsis litteris para o inglês: o termo mais próximo seria homesickness, que em tradução literal corresponderia a 'permanência no lar por licença de adoecimento' - não está nem implícito o sentido de falta de algo ou alguém, ou a noção de desejo deslizante, o que é mais próximo do sentido na língua 
JOSÉ GUILHERME DOS SANTOS FERNANDES - Colaboração intercultural na educação...

portuguesa. Por isso, conhecer minimamente a língua do outro é importante para se realizar a interculturalidade. E me refiro à língua no que ela tem de fundação de uma cultura. Em alguns casos é possível a comparação, mas em outros são impossíveis as aproximações. Também a insistência em traduzir textos de origem (saberes locais) em saber científico leva a uma supervaloração deste, uma vez que essa situação o configura como o pensamento de validação, mesmo sendo texto de destino.

Para além deste aspecto mais cognitivo do diálogo de saberes, há de se considerar que os saberes estão em contexto, ou seja, nesse diálogo é importante o sentir-pensar-fazer. Por isso, deve-se atentar para uma educação dos sentidos, de envolvimento do corpo, em atitude participativa e solidária, pois o aprendizado de alguns saberes se dá de forma coletiva, em visão holística. Ao final, essa experiência pode se objetivar na habilidade para construir artesanías ou de reproduzir/recriar rituais ancestrais; o que aproxima qualidades sensíveis do sujeito e as propriedades de um objeto, conforme LéviStrauss (1997). Observa-se esse envolvimento físico e emocional em práticas como a do professor e antropólogo Jaime Fayad, da Universidade de Cauca, irmão de Javier Fayad, que periodicamente oportuniza a participação de seus alunos em "mingas" (trabalho solidário entre comuneros andinos), no resguardo de Guambía, em Silvia (Colômbia), com a finalidade de propor esse diálogo. Dessa forma também vem ocorrendo o Projeto Encontro de Saberes, iniciativa do antropólogo e professor José Jorge Carvalho, da Universidade de Brasília (UnB, Brasil). Não é propriamente uma ação intercultural "oficial”, mas tem na interculturalidade seu mote, mediante a oferta de práticas da cultura popular (considerada como tradições culturais indígenas e afrobrasileiras) como atividades complementares ao currículo, corrigindo o efeito de espetacularização e canibalização que as culturas populares sofrem (CARVALHO, 2007). Esse desdobramento da prática de diálogo de saberes implica em proposição de instrumentos de avaliação que estão para além da educação convencional; nessa proposição alternativa, deve-se atentar para: a efetiva participação nos rituais/celebrações/festas; a capacidade de improvisação e criação dos alunos; a interação oral e escrita no acesso e reprodução dos textos 
JOSÉ GUILHERME DOS SANTOS FERNANDES - Colaboração intercultural na educação...

ritualísticos; e a performance individual e solidária.

Se por um lado é na universidade que existe maior possibilidade de se efetivarem as ontologias relacionais e o diálogo de saberes, de outro modo também é nesse espaço que existe, com mais frequência, a diversidade de atores e a divisão de saberes, e nessa diversidade e divisão muita tensão pelo poder, que está disfarçada na "objetividade" e no "reconhecimento" do discurso científico:

O capital científico é uma espécie particular do capital simbólico (o qual, sabe-se, é sempre fundado sobre atos de conhecimento e reconhecimento) que consiste no reconhecimento (ou no crédito) atribuído pelo conjunto de pares-concorrentes no interior do campo científico (BOURDIEU, 2004, p. 26).

Talvez dessa compreensão de reconhecimento pelos pares é que decorra a autonomia universitária tão proclamada e o consequente distanciamento e distinção "superior" da ciência, com o consequente menosprezo ou, no máximo, condescendência pelos outros saberes, vistos como inferiores: são estratégias de valorização simbólica (THOMPSON, 1995). Face a toda essa questão de reconhecimento de saberes, fica a dúvida: as universidades próprias também não podem transformar-se em outras universidades "convencionais", a seu modo? Esta é a possibilidade que preocupa Axel Rojas, da Universidade de Cauca, pois, em sua visão, em Colômbia a interculturalidade assumiu um papel muito localizado em relação aos grupos étnicos:

No creo que haya mucha diferencia en Colombia entre universidades indígenas y universidades convencionales. Ambas son convencionales a su manera, es decir, ambas son monoculturales, y casi se podría decir monoétnica, son poco interculturales.

Esta é uma questão a considerar e que trataremos a seguir.

Os desenhos curriculares apontam para um primeiro aspecto comum: o afã de promover a cultura indígena levou à conformação de um currículo bastante atrelado aos estudos antropológicos, em uma afirmação demasiada da cultura ancestral, o que foi corrigido em algumas experiências pesquisadas; lembra Medina (Peru): "estudiamos lo que fue, pero también lo que ha sido, lo que son ahora". O 
JOSÉ GUILHERME DOS SANTOS FERNANDES - Colaboração intercultural na educação...

enquadramento a partir da acentuação do passado é passível de críticas, pois tem o efeito de prescrever o que é ser indígena, a ser demonstrado pelo uso e domínio do idioma, vestuário, ritual, mitos, por exemplo. Para minimizar esse efeito, o FORMABIAP investiu posteriormente em aspectos mais pedagógicos na formação de docentes, o mesmo acontecendo com o CIFMA e as licenciaturas em etnoeducação e em interculturalidade: em geral, os planos de estudo se realizam em metodologia semipresencial ou de alternância, em que há um período de estudos no espaço de formação acadêmico e outro período de atividades nos espaços de origem dos indígenas, momento este em que há um diagnóstico sobre a comunidade e a escola, com posterior problematização da realidade e a elaboração de proposta pedagógica e de intervenção; realiza-se a execução da proposta e finaliza-se o estudo com reflexão e conclusão, o que se configura como trabalho final do curso. Não se esqueceu o caráter etnográfico, o que houve foi uma ampliação deste caráter para uma efetiva intervenção na comunidade, o que pode não agradar muito aos antropólogos mais clássicos, preocupados no distanciamento e na descrição.

De todo modo, a herança da prática etnográfica inicial das propostas estudadas sobrevive na metodologia. Em todas as experiências investigadas está presente na proposição metodológica a interação da escola com a comunidade. Como lembra Marta Corrales (Colômbia), a etnoeducação deve ser uma educação em contexto, por isso deve ocorrer também a partir dos territórios indígenas (resguardos, aldeias, comunidades); daí a necessidade de visitar famílias e identificar temas e histórias de vida, na alternância. A questão é que há dois casos que impedem o encontro com uma cultura mais originária: nem todos os alunos de um curso intercultural são moradores de território indígena ou que dominam minimamente a língua aborígene; e pode haver caso em que o aluno de um curso intercultural seja não indígena, como ocorre na Etnoeducação da Universidade de Cauca (o mesmo não ocorre no caso brasileiro). Então, como fazer? Acredita-se que ambos alunos podem ser investigadores em suas comunidades de origem, uma vez que tratar de questões indígenas pode ser relevante também a partir da cultura não indígena. Uma outra questão a ser explorada como face da alternância é o trabalho eventual de indígenas em instituições públicas e 
de estado, como atividade de extensão: "La Justicia cuando tiene alguna causa o alguno indígena implicado nos envía un pedido a ver qué docente indígena podría oficiar de traductor" (Estela Valenzuela, Argentina).

Os processos seletivos de acesso aos cursos de formação têm se preocupado com as especificidades do público indígena. Via de regra, as seleções se efetivam em: avaliação do domínio de língua e cultura aborígene, aval da comunidade e análise do currículo do candidato; em alguns casos, há uma prova de redação, que pode ser na língua indígena ou na língua oficial (espanhol ou português, conforme o país). Mas o que nos preocupa é a insistência dos ministérios e secretarias de educação em uniformizar os procedimentos de acesso, mesmo em cursos interculturais. No Brasil, algumas universidades já pensam em tornar obrigatório o Exame Nacional do Ensino Médio (ENEM) como instrumento de seleção para as vagas de cotistas indígenas e afrodescendentes, desconsiderando-se o histórico desse público e/ou a finalidade do curso e da realização do mesmo pelo candidato. O que há por trás da questão do acesso é uma política mais ampla dos estados nacionais de uniformização de currículos, que se reflete nas seleções. No Peru, a imposição parcial de currículo único para o FORMABIAP levou a estratégias não tão "oficiais", pois na cultura indígena não se pode separar homem e natureza:

En la normatividad oficial una cosa es naturaleza y otra cosa es sociedad. A pesar de toda la discusión que tuvimos no pudimos lograr lo que sea. Lo que hemos hecho, hecha la ley, hecha la trampa: cuando presentamos en el documento es así, pero cuando trabajamos es diferente (Dubner Medina, Peru).

Uma questão vinculada ao currículo é a avaliação da proposta pedagógica. O exemplo da Licenciatura Intercultural (Brasil) é revelador do despreparo das instituições governamentais (Ministério de Educação/MEC) em relação a propostas de caráter intercultural. Por apresentar três ênfases a partir da metade do curso (Comunicação e Artes, Ciências da Natureza e Ciências Sociais), a licenciatura foi avaliada por três equipes distintas de técnicos do ministério, sem nem ao menos haver uma interação entre as mesmas: 
JOSÉ GUILHERME DOS SANTOS FERNANDES - Colaboração intercultural na educação...

O perfil intercultural da proposta mesmo não tem nenhum diferencial de avaliação. O que deveria ser realmente avaliado, acho que não existe uma discussão no Brasil ainda. O que é que um curso destes tem que ter obrigatoriamente? E o MEC ainda não pensou nisso (Fabíola Carvalho, professora da Licenciatura Intercultural, Núcleo Insikiran/UFRR, Brasil).

Acredita-se que a ausência de avaliação mais particularizada reflete a incapacidade da formação acadêmica convencional dos avaliadores em realizar práticas interdisciplinares.

\section{Conclusões, ou da interculturalidade ao Bom Viver}

Decorrentes das experiências investigadas, apresentam-se as seguintes dificuldades: 1) insuficiência ou inexistência de planificação e de repasse de recursos financeiros por parte do Estado para as instituições, o que dificulta ou minimiza o funcionamento de alojamento e alimentação aos docentes e discentes ou o acompanhamento de atividades nas comunidades; 2) falta de docentes capacitados para o desenvolvimento de educação bilíngue e/ou práticas interculturais/interdisciplinares, uma vez que a proposta requer equipe multidisciplinar; 3) decorrentes do aspecto anterior, inexistência de projetos produtivos realizados pelos formandos, implicando no distanciamento entre teoria e prática; 4) uniformização de currículos, de calendários administrativos e de procedimentos de avaliação por parte do Estado, sem consideração de práticas e processos próprios das comunidades indígenas; 5) supervalorização da escola convencional e de suas práticas por algumas comunidades indígenas, o que compromete a efetivação da proposta intercultural; 6) rigidez de critérios e procedimentos, por agências governamentais, no que se refere ao reconhecimento e acreditação de instituições interculturais, decorrentes principalmente de falácias jurídicas ou de ensimesmamento da academia, sob o discurso da autonomia universitária; 7) dificuldades dos ingressantes por precariedade financeira ou por carência de "alfabetização" formal e/ou científica em suas experiências escolares, ou 
JOSÉ GUILHERME DOS SANTOS FERNANDES - Colaboração intercultural na educação...

por preconceitos de seus pares ou dos docentes envolvidos no processo; 8) dificuldades de acesso dos egressos ao emprego, por burocratização pelo Estado das condições de contratação; 9) carência de material didático apropriado à proposta intercultural, por falta de recursos financeiros e de pessoal capacitado para a produção; e 10) falta de diálogo entre saberes (convencionais ou próprios), o que implica na não inclusão e na hierarquização discriminatória entre eles ${ }^{6}$.

Entende-se, no entanto, que as dificuldades apresentadas antes de serem um desestímulo às propostas interculturais são alavancas desafiadoras para que se promova a interculturalidade na educação superior. Pode-se resumir o estímulo nas palavras da professora Fabíola Carvalho (Núcelo Insikiran, Brasil): "de todo modo, o professor que entra é um, o professor que sai é outro. Tem um percurso aí que eu acho que ele ganha muito". Porque o que está no foco é o conceito de interculturalidade e a aplicabilidade deste às propostas de uma educação renovada, com participação e inclusão, de povos e de saberes. E a ideia de que a interculturalidade é um processo e um encontro, mas também um conflito, está subjacente ao discurso de todos os entrevistados, por isso a necessidade da continuidade, com acertos e desacertos.

Por isso, deve-se entender a interculturalidade em várias vozes:

$\mathrm{Na}$ interculturalidade o primeiro é o conflito; nós estamos falando de um conflito histórico e em uma relação em que se dá um conflito muito pesado. Se trata de fazer um discurso contra-hegemônico no sentido de buscar alternativas mais reais, concretas (Maxim Repetto, Brasil).

Es un proceso y un reto, que tiene una dimensión fundamentalmente política, que tiene que promover el reconocimiento de los saberes de las diversas culturas, que tiene que cuestionar la distribución del poder y establecer una estrategia de redistribución que garantice el ejercicio democrático (Ilana Estabrides, Perú).

Me parece que la interculturalidad es eso: una relación de igual a igual. Es una relación con el otro en

\footnotetext{
${ }^{6}$ Para se ter mais informações acerca de logros, problemas e desafíos em propostas interculturais na América Latina, ver: Mato (no prelo).
} 
JOSÉ GUILHERME DOS SANTOS FERNANDES - Colaboração intercultural na educação...

condiciones de igualdad, donde la singularidad de cada uno se pone en comunicación, en juego, en relación. Donde yo no voy a ser nunca como él ni él nunca va a ser yo (Estela Valenzuela, Argentina).

La pienso como la posibilidad de dialogar, de conversar, de poder construir ideas e intercambiar sentimientos, partiendo de la diferencia. Somos iguales, pero sentimos el mundo de maneras diferentes (Alexandra Obando, Colômbia).

Tão diversos e, ao mesmo tempo, tão confluentes discursos acerca da interculturalidade nos fazem retomar a visão de Mato (2012) ao reconhecer a heterogeneidade das organizações sociais e políticas indígenas conforme os contextos nacionais e as relações com o Estado e os demais atores sociais, o que resulta em diversos discursos sobre as experiências interculturais. Por isso a importância em se reconhecer também que há regiões culturais, com histórias e organizações sociais próprias, em que as experiências se desenvolvem/desenvolveram diferentemente, em modelos hegemônicos, formações intelectuais e culturais e também relações sociais diversas. Não dá para comparar e valorar rasteiramente as experiências interculturais indígenas em populações andinas e em populações amazônicas no Peru, por exemplo. Certo é que passaram por processos colonizadores semelhantes, mas os andinos vêm de experiências mais "integradoras", talvez tocados pela civilização incaica, que teve a preocupação de estabelecer o Qhapaq Nan (sistema viário inca) para imposição de leis, crenças e línguas; os amazônicos ficaram relativamente "esquecidos" pelos colonizadores, isolados pelos governos nacionais até a década de 70 do século $X X$. Quando houve o "desborde popular" (MATOS MAR, 2004) dos andinos em direção a Lima, capital do Peru, a partir de meados do século XX, estes já vinham de uma larga experiência integradora, mesmo que repletos de medos e preconceitos de séculos de imposição dos colonizadores. Assim foi mais fácil tomarem de "assalto" Lima, com a proposição de novas pautas de conduta, valores, atitudes e estilos de vida, em múltiplas formas de organização em novos territórios periféricos urbanos. Daí a diferença entre os indígenas andinos e os indígenas amazônicos em relação às suas capacidades de organização, mobilização e reivindicação de propostas: os primeiros com maior 
JOSÉ GUILHERME DOS SANTOS FERNANDES - Colaboração intercultural na educação...

coesão para o alcance de suas finalidades; os demais, relativamente isolados e com os medos mais recentes da experiência do caucho e atrocidades de Julio Arana e a Peruvian Company, ocorridas na região de Putumayo (Peru), no início do século XX (VALCÁRCEL, 2004).

Deve-se considerar que o avanço da possibilidade de diálogo de saberes e culturas não pode desconhecer e questionar sempre a relação hierárquica entre elas feita pelo sistema universitário, no afã de se instituir o conhecimento comum e prioritário nos currículos. O processo deve dar conta

de la diversidad de modos de imaginación, percepción, cognición y acción de distintos grupos sociales, y de la forma desigual en que están representados en narrativas y prácticas escolares. La interculturalidad, con este horizonte, puede ser recuperada en su sentido crítico y transformador" (DIEZ et al., 2011, p. 274).

A diversidade de experiências pode ser indicativo da procura de alternativas ao desenvolvimentismo, implicando, de outro modo, em convergência nessas experiências. Ao que parece, busca-se o buen vivir, com o pertencimento a um modelo alternativo de sociedade, em vista da falência do modelo ocidental desenvolvimentista. Não é novidade que o modelo desenvolvimentista tem implicado em crises mundiais econômicas, ambientais, políticas e religiosas, pondo em xeque a sociedade capitalista e o saber científico: para que e para quem? Como alternativa aos impactos quase que irreversíveis na sociedade e no meio ambiente, busca-se, a partir do final do século XX, as tradições locais e os movimentos sociais como nova ordem mundial para se obter qualidade de vida ampla para a Humanidade. $E$ as experiências interculturais podem ser indicativo de transição/tradução entre as duas formas de sociedade em contato no início do século XXI: sociedade desenvolvimentista e sociedade do "bom viver"7. A tensão entre estas

\footnotetext{
${ }^{7}$ Para uma consideração do Bom Viver (BV), optamos por Escobar: "el BV pretende introducir una filosofía de vida diferente de la visión de sociedad. Esto hace posible una ética del desarrollo que subordina los objetivos económicos a criterios ecológicos, a la dignidad humana y a la justicia social. El desarrollo como Buen Vivir busca articular la economía, el medio ambiente, la sociedad y la cultura en nuevas formas, llamando a las economías sociales y solidarias mixtas; introduce temas de justicia social e intergeneracional en los espacios de los principios de desarrollo; reconoce las diferencias culturales y de género, posicionando la interculturalidad como principio rector; y permite los nuevos énfasis políticoeconómicos, tales como la soberanía alimentaria, el control de los recursos naturales y un derecho humano al agua (...). El BV también está influenciado por las corrientes críticas del pensamiento
} 
JOSÉ GUILHERME DOS SANTOS FERNANDES - Colaboração intercultural na educação...

duas maneiras de organizar a sociedade gerou a necessidade de mútua tradução, implicando em procedimentos epistemológicos interculturais e interepistêmicos como o processo primordial para estabelecer-se a descolonização do saber. Nesse bojo, a interculturalidade é um caminho possível na composição de alternativa a uma terceira via de sociedade, o que só poderá ser viabilizado também com a organização e fomento de instituições de educação que tragam em suas propostas o encontro de culturas e saberes, com suas tensões e acordos.

\section{Referências bibliográficas}

APARICIO, Pedro Mayor; BODMER, Richard E. Pueblos indígenas de la Amazonía peruana. Iquitos: CETA, 2009.

BOURDIEU, Pierre. Os usos sociais da ciência: por uma sociologia crítica do campo científico. São Paulo: Ed. UNESP, 2004.

CARVALHO, José Jorge. Espetacularização e canibalização das culturas populares. In: I Encontro Sul-Americano das Culturas Populares e II Seminário Nacional de Políticas Públicas para as Culturas Populares. São Paulo: Instituto Polis; Brasília: Ministério da Cultura, 2007. p. 79-101.

CARVALHO, Fábio, FERNANDES, Maria Luiza, REPETTO, Maxim (Org.). Projeto Político-Pedagógico da licenciatura intercultural, Núcleo Insikiran, UFRR. Boa Vista: Editora da UFRR, 2008.

CENTRO DE INVESTIGACIÓN Y FORMACIÓN PARA LA MODALIDAD ABORÍGEN (CIFMA). Plan de estudios de la carrera de professor intercultural bilíngue. Disponível em: http://cifma.cha.infd.edu.ar/sitio/index.cgi?wid_seccion=2\&wid_item=4. Acesso em: 15 jan. 2014.

CENTRO VIRTUAL CERVANTES. Interculturalidad. In: __. Diccionario de términos clave de ELE. s./d. Disponível em: http://cvc.cervantes.es/ensenanza/biblioteca_ele/diccio_ele/diccionario/interculturalidad .htm . Acesso em: 19 fev. 2014.

Constitución de La Nación Argentina. Disponível em:

occidental, y su objetivo es influir en los debates globales. Dicho esto, existe un amplio reconocimiento de que los conocimientos indígenas y afro han sido sometidos a procesos de marginación de larga data, o lo que en algunas de las perspectivas actuales de América Latina se reconoce como 'colonialidad'. El BV, de esta manera, busca revertir la colonialidad del poder, del conocimiento y del ser que han caracterizado al sistema mundo moderno/colonial desde la conquista" (ESCOBAR, 2012, p. 35). 
JOSÉ GUILHERME DOS SANTOS FERNANDES - Colaboração intercultural na educação...

http://www.constitution.org/cons/argentin.htm. Acesso em: 15 jan. 2014.

Constitución Política del Perú. Disponível em: http://www.congreso.gob.pe/ntley/Imagenes/Constitu/Cons1993.pdf. Acesso em: 15 jan. 2014.

Constitución Política de La República de Colombia. Disponível em: http://www.senado.gov.co/images/stories/Informacion_General/constitucion_politica.pd f. Acesso em: 15 jan. 2014.

Constituição da República Federativa do Brasil. Brasília: Senado Federal, Subsecretaria de Edições Técnicas, 2006.

DIEZ, María Laura et al. Interculturalidad y educación: cruces entre la investigación y la gestión. In: NOVARO, Gabriela (Org.). La interculturalidad en debate: experiencias formativas y procesos de identificación en niños indígenas y migrantes. Buenos Aires: Biblos, 2011. p. 265-281.

ESCOBAR, Arturo. La invención del desarrollo. Popayán: Editorial Universidad del Cauca, 2012.

FERNANDES, Maria Luiza, CARVALHO, Fábio de Almeida, REPETTO, Maxim. Acesso e permanência de indígenas ao ensino superior: o Programa E'ma Pia. Boa Vista: Ed. UFRR, 2009.

GLISSANT, Édouard. Introdução a uma poética da diversidade. Juiz de Fora: Ed. UFJF, 2005.

LÉVI-STRAUSS, Claude. O pensamento selvagem. Campinas: Papirus, 1997.

MANDRINI, Raúl. La Argentina aborigen. Buenos Aires: Siglo Veintiuno Editores, 2012.

MATO, Daniel. Não há nenhum saber "universal", a colaboração intercultural é essencial. Alteridade, Cidade do México, 2008a. p. 101-116.

(Org.). Diversidad cultural e interculturalidad en educación superior: experiencias en América Latina. Caracas: IESALC-UNESCO, 2008b.

(Org.). Instituciones Interculturales de Educación Superior en América Latina: procesos de construcción, logros, innovaciones y desafíos. Caracas: IESALCUNESCO, 2009a.

(Org.). Educación Superior, Colaboración Intercultural y Desarrollo Sostenible/Buen Vivir: experiencias en América Latina. Caracas: UNESCO-IESALC, 2009b.

Educación Superior y Pueblos Indígenas y Afrodescendientes en América

Espaço Ameríndio, Porto Alegre, v. 8, n. 1, p. 10-39, jan./jun. 2014. 
JOSÉ GUILHERME DOS SANTOS FERNANDES - Colaboração intercultural na educação...

Latina. Constituciones, Leyes, Políticas Públicas y Prácticas Institucionales”. In: Educación Superior y Pueblos Indígenas y Afrodescendientes en América Latina. Caracas: IESALC-UNESCO, 2012. p. 1-18.

Universidades Indígenas en América Latina: principales características, logros, problemas y desafios. Revista Inclusión Social y Equidad en la Educación Superior, Santiago de Chile, no prelo.

MATOS MAR, José. Desborde popular y crisis del Estado. Lima: Fondo Editorial del Congresso del Perú, 2004.

POCNOLEC. Alumnos del CIFMA Saenz Peña denuncian maltratos y hasta se le da alimentos podridos. 2013. Disponível em: http://pocnolec.blogspot.com.br/2013/03/alumnos-del-cifma-de-saenz-pena.html

Acesso em: 25 jun. 2014.

PROGRAMA DE FORMACIÓN DE MAESTROS BILINGÜES DE LA AMAZONÍA PERUANA (FORMABIAP). Lineamientos Curriculares de Formación Docente en Educación Inicial Intercultural. Iquitos: Instituto Superior Pedagógico Público "Loreto", 2004. Disponível em: http://www.formabiap.org/sitio/images/articulos/PDF/Inicial.pdf.pdf. Acesso em: 15 jan. 2014.

RAMA, Angél. Angél Rama. São Paulo: Editora da USP, 2001.

RAMIREZ, Teresa et al. Educación en comunidades indígenas del nororiente del Cauca. Popayán: Editorial Redipe, 2012.

RAMOS, Alcida Rita (Org.). Constituições nacionais e povos indígenas. Belo Horizonte: Ed. UFMG, 2012.

ROJAS, Axel. ¿Etnoeducación o educación intercultural?: estudio de caso sobre la licenciatura en Etnoeducación de la Universidad del Cauca. In: MATO, Daniel (Org.). Diversidad cultural e interculturalidad en educación superior: experiencias en América Latina. Caracas: IESALC-UNESCO, 2008a. p. 233-242.

ROJAS, Axel (Org.). Cátedra de Estudios Afrocolombianos: aportes para maestros. Popayán: Editorial Universidad del Cauca, 2008b.

THOMPSON, John B. Ideologia e cultura moderna: teoria social crítica na era dos meios de comunicação de massa. Petrópolis: Vozes, 1995.

TRAPNELL, Lucy Ann. La experiencia del Programa de Formación de Maestros Bilingües de la Amazonía Peruana. In: MATO, Daniel (Org.). Diversidad cultural e interculturalidad en educación superior: experiencias en América Latina. Caracas: IESALC-UNESCO, 2008. p. 403-412.

UNIVERSIDAD DEL CAUCA. Programa de Licenciatura en Etnoeducación: plan 
JOSÉ GUILHERME DOS SANTOS FERNANDES - Colaboração intercultural na educação...

de estudios. Disponível em: http://www.unicauca.edu.co/versionP/ofertaacademica/programas-de-pregrado/licenciatura-en-etnoeducacion/plan-de-estudios. Acesso em: 15 jan. 2014.

VALCÁRCEL, Carlos A. El proceso del Putumayo y sus secretos inauditos. Iquitos: CETA, 2004.

VALENZUELA, Estela Maris. Educación Superior Indígena en el Centro de Investigación y Formación para la Modalidad Aborigen (CIFMA): génesis, desarrollo y continuidade. In: MATO, Daniel (Org.). Educación Superior, Colaboración Intercultural y Desarrollo Sostenible/Buen Vivir: experiencias en América Latina. Caracas: UNESCO-IESALC, 2009. p. 79-102. 